\title{
Coping Effects on Life Meaning, Basic Psychological Needs and Well-Being
}

\author{
Margarita Bakracheva \\ Sofia University, St. Kliment Ohridski, Bulgaria \\ Email:m.bakracheva@abv.bg
}

How to cite this paper: Bakracheva, M. (2019). Coping Effects on Life Meaning, Basic Psychological Needs and Well-Being. Psychology, 10, 1375-1395.

https://doi.org/10.4236/psych.2019.1010090

Received: July 1, 2019

Accepted: July 27, 2019*

Published: July 30, 2019

Copyright $\odot 2019$ by author(s) and Scientific Research Publishing Inc. This work is licensed under the Creative Commons Attribution International License (CC BY 4.0).

http://creativecommons.org/licenses/by/4.0/ (c) (i) Open Access

\begin{abstract}
The article outlines the effects of the proactive coping on well-being in a convenient sample comprising 350 Bulgarians, aged 18 - 55. Volunteers were administered self-assessment instruments, describing coping strategies, basic psychological needs, life purpose, resilience, conspiracy beliefs, happiness and life satisfaction. Results reveal that the proactive coping predicts life satisfaction and happiness, autonomy, competence and relatedness as basic needs. Presence of life meaning and search for meaning are confirmed to be quite opposite constructs. Presence of meaning is negatively related to coping strategies and well-being. For this sample adaptive and well-being promoter is search of meaning and less reliance on fixed commitments, expressed in the presence of meaning. This suggests that if person prefers to maintain commitments without further exploration, this prevents development and lowers the level of well-being.
\end{abstract}

\section{Keywords}

Well-Being, Coping Strategies, Life Meaning

\section{Introduction}

Today the more and the more researches evidence the relation between stress and various disorders and that stress has significant effect on psychological well-being and health. The relationship between coping strategies and well-being under stress (Yang, 2010) and the use of approach-oriented coping strategies is significantly predictive of positive psychological well-being (Lee et al., 2019). Stress management and coping strategies are essential for the balanced life. In addition to reactive coping is reported the role of preventive and proactive coping, aimed at conservation of personal resources. Our interest is to trace how the different forms coping can promote subjective well-being. The importance of life 
meaning for well-being is also reported in a number of publications (Urry et al., 2004; Mascaro \& Rosen, 2005; Reker, 2005; Steger \& Frazier, 2005; King et al., 2006; Steger et al., 2006). Recent studies reveal that not personal traits, but rather the context can lead to elevated belief in conspiracy. We consider this rather interesting because of the cultural specificities and the great level of perceived uncertainty in Bulgaria. The context of experienced lack of perspectives and faith in justice for decades explain why Bulgarians turn out to be among the least happy nations in Europe and worldwide (ref. Bakalova et al., 2015, Bakracheva, 2017). This leads us to the question of measuring conspiracy beliefs in relation to coping and most of all, as serving as some form of reactive and/or preventive coping. We are interested also in the relations of coping and resilience. Our objective is to outline the effect of the coping on happiness and life satisfaction, as well as the role of satisfaction of the basic psychological needs, resilience and conspiracy beliefs.

\section{Theoretical Background}

We will describe in brief the research of stress and coping; life meaning, conspiracy beliefs, resilience, and the hedonic and eudemonic approaches to well-being, underlying the study.

\subsection{Stress and Coping Strategies}

Biological stress model underlies the psychological theories of coping style and strategies. The focus first had been on the two basic emotions, fear and anger, that prepare the organism for reaction. This biological reaction is well known as "fight or flight", aiming to overcome the stressful situation. Selye defines the stress as a non-specific response of the body to all external requirements (Selye, 1976). He is one of the first researchers who gives attention to the biological stress and evidences that stress makes people vulnerable to a number of diseases.

Coping became of key interest for psychologists during the second half of the past century. As a general term, coping relates to the psychoanalytical defensive mechanisms, described in the behaviour, avoiding threats to the Self. Within the psychodynamic approach is suggested the hierarchical model of the coping, treating the defences as healthy behaviour (Menninger, 1954; Haan, 1977; Vaillant, 1977). In the end of the 70s the hierarchical approach and traits approach have been displaced by the concept of coping as a process. Coping is perceived as changing in time depending on the specificity of the situations and the context. Cognitive-phenomenological approach considers the coping two-stage, comprising cognitive processing of the information about the stressful situation and assessment of the available coping resources. These stages relate to the behavioural efforts, aimed at mastery, acceptance or decrease of the external and internal needs and the conflicts between them. Coping has two main functions: management of the human-environment transactions that are the source of stress (problem focused coping) and regulation of the emotions, evoked by the 
stress (emotion focused coping). The possible ways of the response or coping are problem or emotion focused engagement or disengagement (Lazarus, 1966; Folkman \& Lazarus, 1980; Lazarus \& Folkman, 1984). Preferences to one strategy is a function of the assessment process: events that are assessed as providing less possibilities for favourable change, will more probably provoke emotion focused coping, whereas events, assessed as giving options for improvement through personal efforts, will probably predict problem focused coping responses. Nevertheless coping strategies cannot be divided into "good" and "bad" (Wrosch et al., 2003), active engagement with problems and search of support are related to better physical and physic health, while avoidance usually has negative effect (Compas et al., 2001; Connor-Smith \& Frachsbart, 2007).

Most important seems to be the issue of coping resources. The conservation theory postulates that main point for investment is not the result itself, but the maintenance of adequate level of recourses (Hobfoll \& Leiberman, 1987; Hobfoll \& Lilly, 1993).

Coping strategies describe the personal self-perceptions and the behaviour aimed at maintaining balance in the course of the individual development and adaptation to the requirements of the environment. Traditional approach to coping is tracing reactive responses, used to diminish distress. In contrast, preventive and proactive coping involve goal setting and are associated with resources for self-improvement. Behaviour is preconditioned by reactions in response to external events, but also by strive after circumventing, getting ahead and preparing for the forthcoming events. The reactive and proactive strategies are interconnected and often translated one into the other. We are interested in the process of awareness and choice of coping strategies mainly in result from the changes, provoked by the interrelated inner stimuli and external factors. We suggest the idea that the successful reactive coping strategies can become a part of the identity in the form of proactive coping strategies (ref. Bakracheva, 2017).

\subsection{Meaning of Life and Search for Meaning}

Meaning is an important part of eudaimonic well-being, supporting the intrinsic motivation in general. Living a meaningful and purposeful life has been shown to be one of the central factors, associated with psychological well-being (Ryff \& Singer, 1998). A great body of research support the link between meaning in life and well-being (Urry et al., 2004; Mascaro \& Rosen, 2005; Reker, 2005; Steger \& Frazier, 2005; King et al., 2006; Steger et al., 2006). Conversely, a lack of meaning in life is associated with a variety of negative outcomes (Mascaro \& Rosen 2005, 2006).

Search for meaning correlates positively with well-being, while other research suggests the contrary relation of dysfunction-only people who are frustrated, are active in the search for meaning (Baumeister, 1991; Klinger, 1998). Recently the position affirmed is that search for meaning can be viewed both positively as life-affirmation and as deficit-based motivation (Reker, 2000). The first model of 
this relation posits that meaning in life is a highly desired psychological quality; when people feel their lives have little meaning, or when they lose meaning, they will search for it. The predicted inverse relation is empirically supported (Steger et al., 2006). Generally, people who possess psychological strengths (e.g. autonomy), are more likely to experience presence of meaning. The second model posits that seeking meaning leads to experiencing greater meaning (Frankl, 1969, 2006). As such, search for meaning should be positively related to presence of meaning. According to a third group of researchers, search for meaning comprises the healthy trend of self-promoting search and the unhealthy trend, underlined by deficit needs (Reker, 2000). A healthy search is usually depicted as grounded in people's aspirations and insights they derive from engaging life's challenges (Maddi, 1970). In contrast, a dysfunctional search is usually said to be marked by people's inability to engage with and resolve negative or challenging experiences (Klinger, 1998). Empirical data evidence that people who lack meaning, search for it; however the search for meaning is not directly leading to its presence (Steger et al., 2008). The path is reverse-lesser presence of meaning leads to greater search for meaning (Steger et al., 2006).

In summary, one of the models suggests that search for meaning in life is a desired psychic state when people fail to perceive their life as meaningful or perceive it as lost its meaning, which determines conscious search for purpose and meaning (Steger et al., 2006). According to the other model search for meaning ensures more meaning and its experience (Maddi, 1970; Ryff, 1989), but lack of meaning provokes negative affects (Mascaro \& Rosen, 2005; 2006). Search for meaning is based on different underlying motivations in different people (Steger et al., 2008). We support this position as more rational, as the individual situation and subjective perceiving are rather various.

\subsection{Conspiracy Beliefs}

Belief in conspiracy theories in general reveals the shared opinion that a large number of the significant events are result from secret/conspiracy plot, carried out by a group of people (Brotherton \& French, 2014). During the recent years the research interest has raised and maybe one of the explanations is in the concept itself-it is not only complicated and predicted by a number of individual, situational and macro-factors, but covers a rather wide range of issues.

The early research relates conspiracy beliefs to feeling of powerlessness and disadvantage, especially in terms of crisis, lack of information or erroneous and unreliable information. Thus, they ensure a convenient alternative to living with uncertainty (Swami et al., 2011). Like other concepts, first negative trends had been outlined, eg. ideation relation to inability to attain specific goals, coping with persecution, reasserting individualism, or expressing negative feelings. Later another point of view had been proposed: conspiracy theories and beliefs are viewed as an attempt the uncertain and complex phenomena, out of personal control, to be understood. 
The explanation, given in the small body of research, is that conspiracy beliefs are related to feeling of powerless or disadvantage position, particularly in terms of crisis or lack of information or when the information is not reliable. One of the more important conclusions is that people who support one conspiracy belief, are more inclined to support and share others as well (Swami et al., 2011). Our previous results replicate that sharing one conspiracy belief promotes such orientation in general, however this depends except for the individual situation, on the subjective feeling about the situation and how dangerous it perceived by the respondents (Bakracheva \& Totseva, 2018). In our approach, we are challenged by the concept of conspiracy ideation perceived as a manifestation of an underlying conspiracy mentality or conspiratorial mindset (Dagnall et al., 2015). We employ two-level differentiation-between beliefs in magic and in particular events and beliefs that form a higher-order belief system. General magic comprise the common beliefs-broken mirror, the Figure 13, etc. In "concrete magic" we include nationally specific beliefs. And for conspiracy mindset we include conspiracy beliefs e.g., that AIDS is intentionally spread, that financial issues are resolved by a few people worldwide, etc. We suggest that conspiracy beliefs can be twofold in positive and negative aspect. The positive aspect is that they are supposed to be related to coping strategies.

\subsection{Resilience}

Resilience is the ability individual to bounce back or recover from stress. Its determinants include biological, psychological, social and cultural factors that interact and determine responses to stressful experiences. In defining resilience, it is important to specify whether resilience is being viewed as a trait, a process, or an outcome (Southwick et al., 2014).

Resilience is a continuum that may be manifested to different degrees across multiple life domains (Pietrzak \& Southwick, 2011). An individual, who adapts well to stress in a workplace or in an academic setting, may fail to adapt well in personal life or in relationships. Furthermore, resilience may change over time as a function of development and individual's interactions with the environment (Kim-Cohen \& Turkewitz, 2012). In addition, our response to stress and trauma takes place in the context of interactions with other human beings, available resources (Walsh, 2006; Sherrieb et al., 2010), and different settings.

\subsection{Well-Being}

The eudaimonic well-being is the strive after self-actualization and revealing one's full potential, conceptualized in the classical theory of self-actualization (Maslow, 1954) as a natural and dynamic life-long process of growth with full concentration and absorption. Reiss \& Havercamp (2005) suggest that 36 years is the reasonable cut-point of the specific age for the attainment of self-actualization. The lifespan approach also considers middle age the period for effective self-reflection, re-assessment, and finding the balance between the in- 
trinsic motivation and social norms (Huyck, 1993; Shek, 1996; Lachman, 2004). Eudaimonic well-being is related to satisfaction of the basic psychological needs. Basic psychological need is considered innate and its satisfaction is said to represent a universally essential experience for well-being (Ryan \& Deci, 2000). Satisfaction of the basic psychological needs for autonomy, relatedness, and competence, contributes to health and psychological well-being. Relatedness satisfaction refers to the experience of intimacy and genuine connection with others, whereas relatedness frustration involves the experience of relational exclusion and loneliness. Competence satisfaction involves feeling of being effective and capable to achieve desired outcomes (Ryan, 1995), whereas competence frustration involves feelings of failure and doubts about one's efficacy. Finally, autonomy refers to the experience of self-determination, full willingness, and volition when carrying out an activity. In contrast, autonomy frustration involves feeling of being controlled by externally enforced or self-imposed pressures (Deci \& Ryan, 1985).

Hedonic well-being is the subjective or emotional well-being, comprising the components happiness, life-satisfaction and positive-negative affect balance (Diener, 1984). Concerning the emotional component of well-being the sustainable happiness model postulates that personal chronic happiness level can be increased and sustained afterwards. Both hedonic and eudaimonic activities should be pursued for the most optimal and diverse well-being (Huta \& Ryan, 2010).

\section{Present Study}

The objective of the study is to trace the relations and effects of coping, psychological needs, resilience, life meaning and conspiracy beliefs on happiness and life satisfaction in adolescence and adulthood. Our expectations are: 1) coping to predict psychological needs, life meaning and well-being; 2) psychological needs, resilience, and life meaning to predict conspiracy and well-being.

Data were collected in March-April 2019. The received complete answers were from distributed 600 paper-and-pencil forms. A cross-sectional predictive research design was carried out. Data were analysed by reliability analyses, descriptive statistics, ANOVA, correlation, linear and multiple regression analyses (IBM SPSS Statistics 25).

\subsection{Sample}

The convenience sample comprises 531 volunteers aged $18-60: 23 \%$ men and $77 \%$ women; $22 \%$ aged 18 - 25, 33\% aged 26 - 35; 34\% aged 36 - 45 and $11 \%$ above 45 years of age. $76 \%$ are working, $16 \%$ are studying and $8 \%$ neither work, nor study. In respect to subjective assessment of their incomes, $20 \%$ of the respondents assess them as lower that average, $60 \%$ as average and $20 \%$ as higher than the average. 


\subsection{Instruments}

The Meaning in Life Questionnaire (MLQ) (Steger et al., 2006): a 10-item self-report scale, designed to measure life meaning, with 5 items for presence and 5 for search of meaning respectively and 5 -point Likert scale with answers from strongly agree to strongly disagree.

Attitudes to magic and conspiracy theories scale: comprises 20 items and 5-point Likert scale with answers from strongly agrees to strongly disagree (Bakracheva \& Totseva, 2018). The items are grouped into three subscales, measuring belief in general magic, belief in particular magic, and general conspiracy attitudes.

Coping is measured with the Proactive Coping Inventory (PCI): A Multidimensional Research Instrument (Greenglass et al., 1999). Coping scale comprises seven subscales: proactive coping-14 items, reflective coping-11 items, strategic planning-4 items, preventive coping-10 items, instrumental support seeking -8 items, emotional support seeking -5 items and avoidance- 3 items We have modified the Likert response scale from 4 to 5 points-with middle "neither true, not untrue in view scales for responses to be identical for all instruments.

Basic Psychological Need Satisfaction and Frustration Scale (BPNSNF), (Chen et al., 2015), comprising 24 items for each subscale-autonomy, competence, and relatedness satisfaction and frustration with 5-point Likert response scale from "not true at all" to "completely true".

The Brief Resilience Scale (BRS) (Smith et al., 2008) comprises 6 items with 5-point Likert response scale from "strongly agree" to "strongly disagree".

The happiness self-report scale we use includes 5-items for experienced happiness in general, during the last year, during the last week, in comparison with friends, and in comparison with virtual friends and 5 response options: "very happy", "happy", "neither happy nor unhappy", "unhappy" and "very unhappy".

The Satisfaction with Life Scale (SwLS) (Diener et al., 1985), a five-item measure that assesses an individual's global judgement of life satisfaction as a whole. We modified the response scale from 7 to 5-point, from "strongly agree" to "strongly disagree".

\subsection{Variables}

We have 18 psychological variables-in respect to coping seven variables: proactive coping, preventive coping, reflective coping, strategic planning, instrumental support, emotional support, and avoidance; three variables for the basic psychological needs: autonomy, competence, and relatedness; two variables for the life purpose: presence of meaning and search for meaning; three variables concerning conspiracy beliefs: sharing beliefs in general magic, in concrete magic, conspiracy mindset; happiness, life satisfaction, and resilience. We have includes also four demographic variables: sex, age, occupation, and incomes. 
Figure 1 outlines all the 18 variables and the model of the studied relations and effects.

\section{Results}

\subsection{General}

We will describe first the descriptive statistics, afterwards effect of the demographic variables, correlations and main effects and predictors of well-being. All variables are normally distributed. Table 1 summarizes the descriptive statistics and reliability of the scales.

All scales have good reliability and component analysis results confirming the original measures. Concrete magic, presence of meaning and avoidance coping have mean below the middle point. All other variables have means above the middle point.

Paired samples statistics reveal that subjective assessment of overall happiness and general satisfaction with life are higher compared to when subjects compare themselves to their friends ( $M$ happiness 4,09 vs. $3.50(t=5.342 ; \mathrm{p}<0.000)$ and $\mathrm{M}$ life satisfaction 4.04 vs. 3.61; $(\mathrm{t}=4.195 ; \mathrm{p}<0.000))$.

Results from the T-Test reveal that search of meaning have higher value compared to presence of meaning. Proactive coping has significantly higher mean values compared to reflective coping, strategic planning, preventive coping, instrumental and emotional support seeking and avoidance coping. Reflective coping has significant differences and is higher compared to strategic planning, preventive coping, instrumental support seeking, and avoidance coping. Avoidance

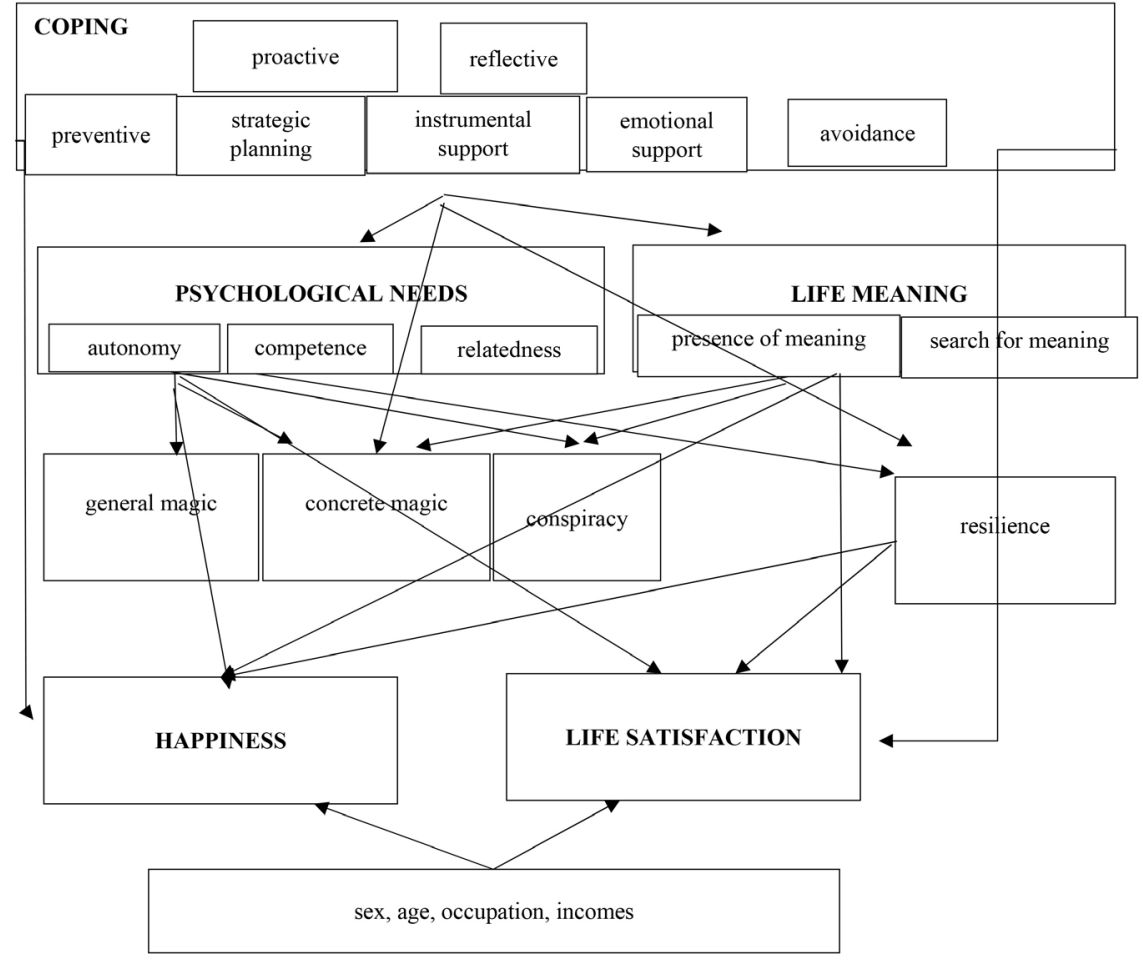

Figure 1. Study variables and expected relations. 
Table 1. Descriptive statistics.

\begin{tabular}{|c|c|c|c|c|c|}
\hline & Min & Max & Mean & $\begin{array}{c}\text { Std. } \\
\text { Deviation }\end{array}$ & $\begin{array}{c}\text { Cronbach's } \\
\text { alpha }\end{array}$ \\
\hline Proactive coping & 1.29 & 5.00 & 3.87 & 0.72 & 0.90 \\
\hline Reflective coping & 1.27 & 5.00 & 3.56 & 0.72 & 0.88 \\
\hline Strategic planning & 1.00 & 5.00 & 3.30 & 0.86 & 0.79 \\
\hline Preventive coping & 1.20 & 4.90 & 3.22 & 0.72 & 0.82 \\
\hline Instrumental support seeking & 1.00 & 5.00 & 3.34 & 0.78 & 0.85 \\
\hline Emotional support seeking & 1.00 & 5.00 & 3.39 & 0.86 & 0.78 \\
\hline Avoidance coping & 1.00 & 5.00 & 2.24 & 0.96 & 0.74 \\
\hline Life satisfaction & 1.00 & 5.00 & 4.05 & 0.97 & 0.66 \\
\hline Happiness & 1.00 & 5.00 & 4.09 & 0.97 & 0.69 \\
\hline Presence of meaning & 1.00 & 5.00 & 2.19 & 0.97 & 0.83 \\
\hline Search for meaning & 1.00 & 5.00 & 3.04 & 10.12 & 0.88 \\
\hline Resilience & 1.17 & 5.00 & 3.39 & 0.78 & 0.82 \\
\hline Autonomy & 1.33 & 5.00 & 4.10 & 0.89 & 0.83 \\
\hline Competence & 1.33 & 5.00 & 3.99 & 0.89 & 0.81 \\
\hline Relatedness & 1.67 & 5.00 & 3.51 & 0.88 & 0.70 \\
\hline General magic & 1.00 & 5.00 & 3.31 & 0.93 & 0.85 \\
\hline Concrete magic & 1.00 & 4.75 & 2.43 & 0.81 & 0.87 \\
\hline Conspiracy & 1.40 & 5.00 & 3.51 & 0.84 & 0.88 \\
\hline
\end{tabular}

coping is significantly lower also compared to strategic planning, preventive coping, instrumental and emotional support seeking (Table 2).

\subsection{Effect of Sex, Age, Occupation and Incomes}

The only effect of sex is on happiness-for this sample women report to be happier compared to men $(t=-2.256 ; \mathrm{p}<0.027 ; \mathrm{M}$ women 4.19 vs. $\mathrm{M}$ men 3.57 respectively). Age has a very limited effect solely on belief in general magic-the group aged 26 - 35 years believe more in magic compared to the group below 25 years of age (mean difference, 55752; $\mathrm{p}<0.043$ ). Incomes have effect solely in respect to avoidance coping-the group considering their incomes low is much more preferring avoidance coping compared to groups reporting their incomes as average and high (mean differences 1.01176; $\mathrm{p}<0.008$ and 1.01176; $\mathrm{p}<$ 0.018). And at last, occupation has also very limited effect-solely on emotional support seeking, whereas those who study feel better to seek emotional support compared to unemployed (mean difference 82857, $\mathrm{p}<0.049$ ).

\subsection{Correlations}

In Table 3 are presented the correlations among the variables.

Coping variables have the expected positive correlations, except for the negative relation between avoidance coping and all other coping strategies. Proactive 
Table 2. Variables differences.

\begin{tabular}{lcc}
\hline \multicolumn{1}{c}{ Variables } & t Mean & Sig. (2-tailed) \\
\hline presence of meaning-search for meaning & -0.84647 & 0.000 \\
proactive coping_-reflective coping & 0.31360 & 0.000 \\
proactive coping-strategic planning & 0.56975 & 0.000 \\
proactive coping-preventive coping & 0.65445 & 0.000 \\
proactive coping-instrumental support seeking & 0.52710 & 0.000 \\
proactive coping-emotional support seeking & 0.47622 & 0.000 \\
proactive coping-avoidance coping & 1.63445 & 0.000 \\
reflective coping-strategic planning & 3.311 & 0.001 \\
reflective coping-preventive coping & 4.309 & 0.000 \\
reflective coping-instrumental support seeking & 2.228 & 0.029 \\
reflective coping-avoidance coping & 9.584 & 0.000 \\
strategic planning-avoidance coping & 7.024 & 0.000 \\
preventive coping-avoidance coping & 7.567 & 0.000 \\
instrumental support seeking-avoidance coping & 7.797 & 0.000 \\
emotional support seeking—avoidance coping & 7.541 & 0.000 \\
\hline
\end{tabular}

coping has high positive relation has with life satisfaction and happiness, resilience, autonomy, competence, and relatedness and positive relations with reflective coping, strategic planning, preventive coping, instrumental support seeking and emotional support seeking. It correlates negatively with avoidance coping, concrete magic. Important to be noted is the high negative correlation with presence of meaning.

Reflective coping has strong positive relations with strategic planning, preventive coping, competence, relatedness and moderate with instrumental support seeking, emotional support seeking, life satisfaction, happiness, resilience, autonomy. There is the same negative correlation with presence of meaning.

Strategic planning correlates positively with preventive coping, emotional support seeking, life satisfaction, happiness, autonomy, competence, and relatedness. It has negative correlation with presence of meaning.

Preventive coping is positively related to instrumental support seeking, emotional support seeking, life satisfaction, autonomy, competence and negatively related to presence of meaning.

Instrumental support seeking is positively related to emotional support seeking, life satisfaction, competence and relatedness.

Emotional support seeking correlates negatively with concrete magic and presence of meaning and positively with life satisfaction, happiness, resilience, autonomy, competence and relatedness.

Interestingly, avoidance coping has positive correlations with general magic, concrete magic, and presence of meaning. Avoidance coping has strong negative 


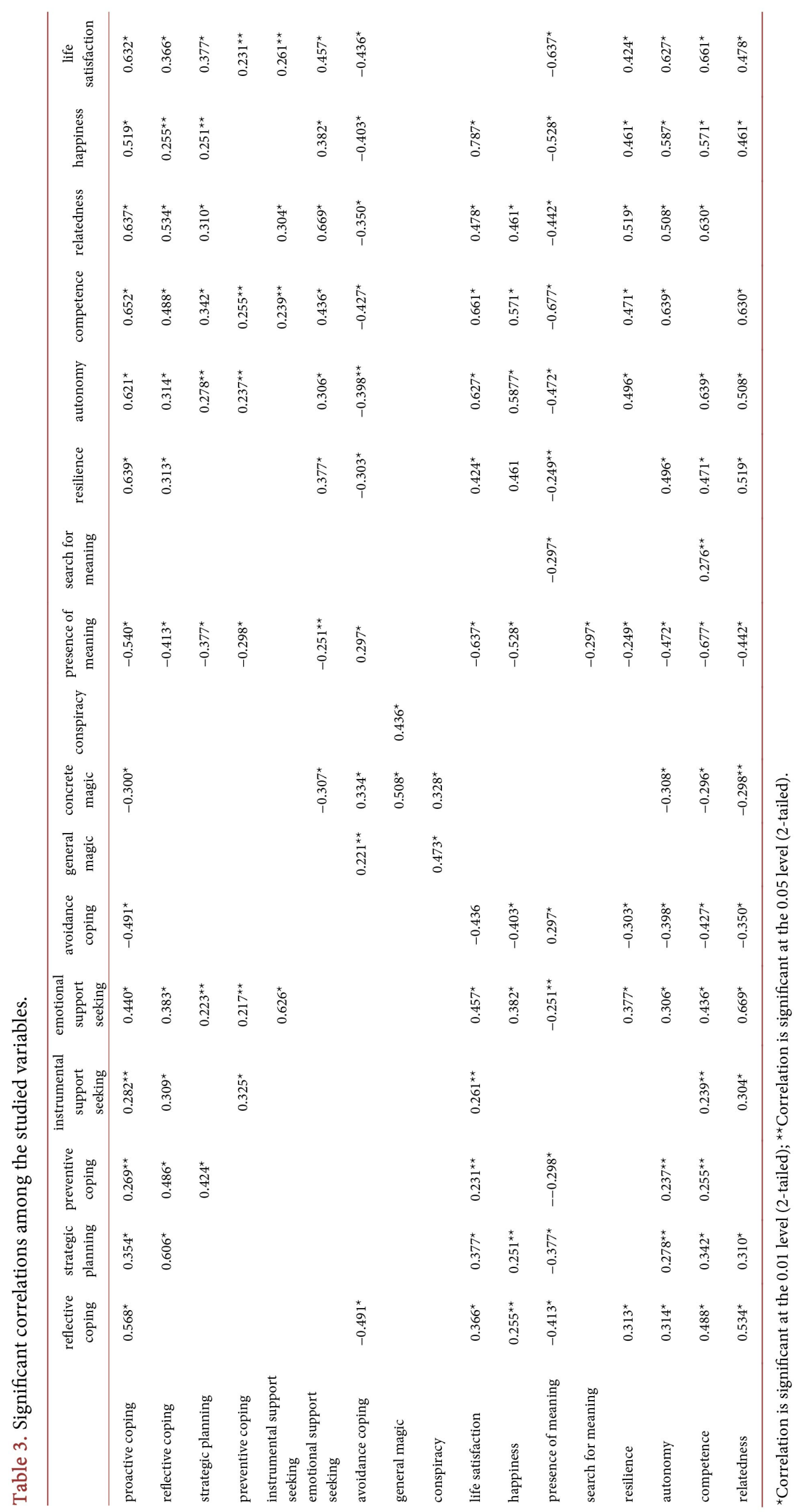


relations with reflective coping, life satisfaction, happiness, resilience, autonomy, competence and relatedness.

Belief in general magic is related to belief in concrete magic and conspiracy. Concrete magic is positively related to conspiracy, general magic, and avoidance coping. It is negatively related to proactive coping, emotional support seeking, autonomy, competence and relatedness.

Life satisfaction is strongly related to proactive and reflective coping, strategic planning, emotional and instrumental support seeking, resilience, autonomy, competence, relatedness, and happiness and negatively to avoidance and presence of meaning.

Happiness is positively related to proactive coping, reflective coping, strategic planning, emotional support seeking, life satisfaction, resilience, autonomy, competence and relatedness. It correlates negatively with avoidance coping and presence of meaning, which suggests that coping relates to the emotional well-being as well, except for preventive coping and the daily instrumental support seeking, related to the cognitive component.

Presence of meaning has positive relation to avoidance coping and correlates negatively with proactive coping, reflective coping, strategic planning, emotional support seeking, life satisfaction, resilience, autonomy, competence, relatedness. Moreover, it correlates negatively also with search for meaning.

Resilience correlates positively with proactive coping, reflective coping, emotional support seeking, life satisfaction, autonomy, competence, relatedness, and happiness. It has negative relation with avoidance coping and presence of meaning.

Autonomy has positive relations with proactive coping, reflective coping, strategic planning, preventive coping, emotional support seeking, resilience, competence, relatedness and happiness life satisfaction. It correlates negatively with avoidance coping, concrete magic, and presence of meaning.

Competence is positively related to proactive coping, reflective coping, strategic planning, preventive coping, instrumental support seeking, emotional support seeking life satisfaction, and relatedness. It is negatively related to avoidance coping and concrete magic.

Relatedness correlates positively with proactive coping, reflective coping, strategic planning, instrumental support seeking, emotional support seeking, resilience, autonomy, happiness, and life satisfaction. It correlates negatively with avoidance coping, concrete magic and presence of meaning.

\subsection{Main Effects and Predictors of Happiness and Life Satisfaction}

All main effects, outlined with linear regression, are described in Figure 2.

Belief in general/concrete magic and conspiracy are not dependent neither on happiness, nor on satisfaction, resilience, autonomy, competence, and relatedness. Coping strategies have no effect on conspiracy, however have on belief in magic. $18 \%$ of the variance in general magic is explained by coping strategies $\left(\Delta \mathrm{R}^{2}=0.18 ; \mathrm{F}=2.435 ; \mathrm{p}<0.026 ; \mathrm{CI}=95 \%\right)$ with individual effect of preventive 


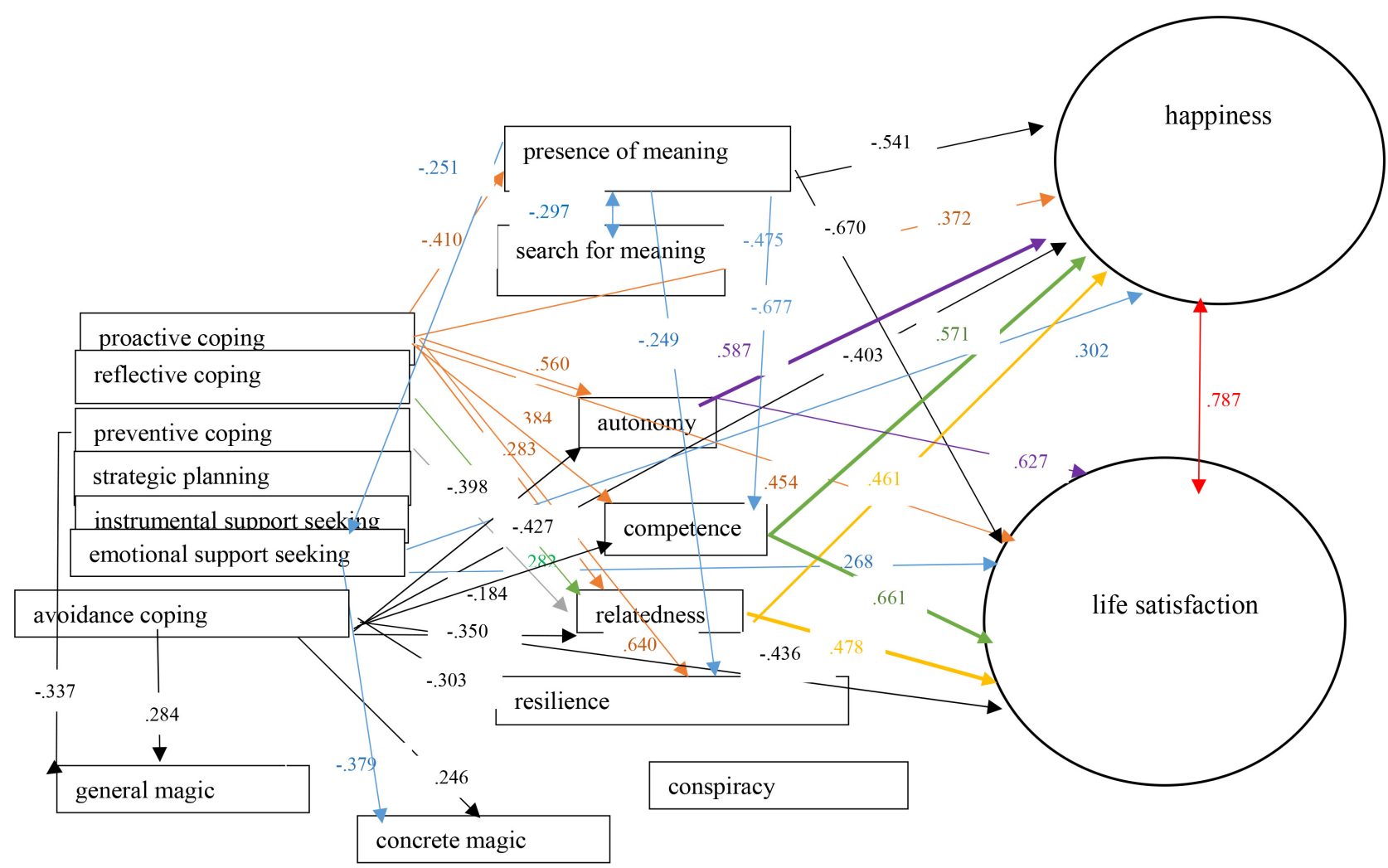

Figure 2. Main effects of the variables.

and avoidance coping. More avoidance and less preventive coping increase belief in general magic. Coping strategies explain $23 \%$ of the variance in concrete magic $\left(\Delta \mathrm{R}^{2}=0.23 ; \mathrm{F}=3.278 ; \mathrm{p}<0.004 ; \mathrm{CI}=95 \%\right)$. The individual effects are of avoidance coping and emotional support seeking. Less emotional support seeking and more avoidance predict belief in concrete magic.

For life satisfaction coping strategies account for $49 \%$ of the variance $\left(\Delta \mathrm{R}^{2}=\right.$ $0.49 ; \mathrm{F}=10.769 ; \mathrm{p}<0.000 ; \mathrm{CI}=95 \%)$. Individual effect is of proactive coping and emotional support seeking. They both predict life satisfaction. The percent of variance in happiness, explained by coping strategies, is $35 \%\left(\Delta \mathrm{R}^{2}=0.35 ; \mathrm{F}=\right.$ 6.126; $\mathrm{p}<0.000 ; \mathrm{CI}=95 \%$ ). The individual effect is again of proactive coping and emotional support seeking. They predict also happiness.

Coping strategies explain $34 \%$ of the variance in presence of meaning $\left(\Delta \mathrm{R}^{2}=\right.$ $0.34 ; \mathrm{F}=5.738 ; \mathrm{p}<0.000 ; \mathrm{CI}=95 \%)$ with individual effect solely of proactive coping. The less is the proactive coping, the more is the presence of meaning. Coping has no effect on search of meaning.

Coping explains $45 \%$ of the variance in resilience $\left(\Delta \mathrm{R}^{2}=0.45 ; \mathrm{F}=8.996 ; \mathrm{p}<\right.$ 0.000 ; $\mathrm{CI}=95 \%$ ). Again the only individual effect is of proactive coping. High proactive coping predicts resilience.

Coping has effect on basic psychological needs. For autonomy the explained percent of variance is $43 \%\left(\Delta \mathrm{R}^{2}=0.43 ; \mathrm{F}=8.295, \mathrm{p}<0.000 ; \mathrm{CI}=95\right)$ with the only individual effect of proactive coping. $49 \%$ of the variance in competence is 
explained by coping strategies $\left(\Delta \mathrm{R}^{2}=0.49 ; \mathrm{F}=10.862, \mathrm{p}<.000 ; \mathrm{CI}=95\right)$. Again, the only individual effect is of proactive coping. Proactive coping predicts autonomy and competence. $67 \%$ of variance in relatedness is explained by coping strategies $\left(\Delta \mathrm{R}^{2}=0.67 ; \mathrm{F}=22.234, \mathrm{p}<0.000 ; \mathrm{CI}=95\right)$. Individual effects have proactive coping, reflective coping, and preventive coping, which predict better relatedness.

Avoidance coping explains $16 \%$ of happiness $\left(\Delta \mathrm{R}^{2}=0.16 ; \mathrm{F}=16.049 ; \mathrm{p}<\right.$ $0.000 ; \mathrm{CI}=95 \%)$ and $19 \%$ of the variance in life satisfaction $\left(\Delta \mathrm{R}^{2}=0.19 ; \mathrm{F}=\right.$ 19.454; $\mathrm{p}<0.000 ; \mathrm{CI}=95 \%)$. It explains $1 \%$ of resilience, $\left(\Delta \mathrm{R}^{2}=0.01 ; \mathrm{F}=8.367\right.$; $\mathrm{p}<0.006 ; \mathrm{CI}=95 \%), 15 \%$ of autonomy $\left(\Delta \mathrm{R}^{2}=0.15 ; \mathrm{F}=15.579 ; \mathrm{p}<0.000 ; \mathrm{CI}=\right.$ $95), 17 \%$ of the variance in competence $\left(\Delta \mathrm{R}^{2}=0.17 ; \mathrm{F}=18.359 ; \mathrm{p}<0.000 ; \mathrm{CI}=\right.$ $95)$, and $12 \%$ of the variance in relatedness $\left(\Delta \mathrm{R}^{2}=0.12 ; \mathrm{F}=11.619 \mathrm{p}<0.000 ; \mathrm{CI}\right.$ =95). All effects are reverse - the more is the avoidance, the lower are the happiness, life satisfaction, resilience, autonomy, competence and relatedness.

Basic psychological needs predict happiness and life satisfaction. Relatedness explains $21 \%$ of the variance in happiness $\left(\Delta \mathrm{R}^{2}=0.21 ; \mathrm{F}=22.441 ; \mathrm{p}<0.000 ; \mathrm{CI}\right.$ $=95 \%)$ and $23 \%$ of the variance in life satisfaction $\left(\Delta \mathrm{R}^{2}=0.23 ; \mathrm{F}=24.639 ; \mathrm{p}<\right.$ $0.000 ; \mathrm{CI}=95 \%)$. The higher is the relatedness, the higher are happiness and life satisfaction. Competence explains $43 \%$ of the variance in life satisfaction $\left(\Delta \mathrm{R}^{2}=\right.$ $0.43 ; \mathrm{F}=64.412 ; \mathrm{p}<0.000 ; \mathrm{CI}=95 \%)$ and $32 \%$ of the variance in happiness $\left(\Delta \mathrm{R}^{2}\right.$ $=0.32 ; \mathrm{F}=40.254 ; \mathrm{p}<0.000 ; \mathrm{CI}=95 \%)$. Autonomy explains $34 \%$ of the variance in happiness $\left(\Delta R^{2}=0.34 ; F=43.610 ; p<0.000 ; C I=95 \%\right)$ and $39 \%$ of the variance in life satisfaction $\left(\Delta \mathrm{R}^{2}=0.39 ; \mathrm{F}=53.796 ; \mathrm{p}<0.000 ; \mathrm{CI}=95 \%\right)$.

Presence of meaning predicts lower resilience $\left(\Delta \mathrm{R}^{2}=0.05 ; \mathrm{F}=5.505 ; \mathrm{p}<\right.$ $0.021 ; \mathrm{CI}=95 \%)$ competence $\left(\Delta \mathrm{R}^{2}=0.46 ; \mathrm{F}=70.145 ; \mathrm{p}<0.000 ; \mathrm{CI}=95 \%\right)$ and emotional support seeking $\left(\Delta \mathrm{R}^{2}=0.06 ; \mathrm{F}=5.558 ; \mathrm{p}<0.021 ; \mathrm{CI}=95 \%\right)$.

Happiness and life satisfaction strongly predict each other $\left(\Delta \mathrm{R}^{2}=0.62 ; \mathrm{F}=\right.$ 135.448; $\mathrm{p}<0.000 ; \mathrm{CI}=95 \%$ ).

The stepwise model reveal that predictors of happiness, explaining $63 \%$ of the variance are life satisfaction (standardized beta 0.722 ) and resilience (standardized beta 0.155$)\left(\Delta \mathrm{R}^{2}=0.63 ; \mathrm{F}=72.813, \mathrm{p}<0.000 ; \mathrm{CI}=95\right)$. Happiness is higher when the perceived life satisfaction and resilience are higher.

Predictors of life satisfaction, explaining $70 \%$ of the variance, are happiness (standardized beta 0.553 ), proactive coping (standardized beta 0.224 ) and presence of meaning (standardized beta -0.255$)\left(\Delta \mathrm{R}^{2}=0.71 ; \mathrm{F}=19.146, \mathrm{p}<0.000\right.$; $\mathrm{CI}=95$ ). Life satisfaction is promoted by proactive coping behaviour and happiness and when there is less presence of meaning (Table 4).

The hierarchical regression analysis and looking for mediation effects with Process have not reported additional statistically significant results.

In summary, proactive coping is the most preferred coping style for this sample, followed by the reflective coping. Preventive coping, strategic planning, instrumental and emotional support seeking seem to be significant on daily level. Avoidance coping turns out to have negative effect on the psychological 
Table 4. Predictors of happiness and life satisfaction.

\begin{tabular}{|c|c|c|c|}
\hline Model & Standardized Coefficients Beta & $\mathrm{t}$ & sig. \\
\hline life satisfaction & 0.722 & 9.862 & 0.000 \\
\hline resilience & 0.155 & 2.118 & 0.037 \\
\hline adjusted $\mathrm{R}$ square & \multicolumn{3}{|c|}{0.631} \\
\hline $\mathrm{F}$ & \multicolumn{3}{|c|}{72.813} \\
\hline sig. & \multicolumn{3}{|c|}{0.000} \\
\hline Model & Standardized Coefficients Beta & $\mathrm{t}$ & sig. \\
\hline (Constant) & & 2.108 & 0.038 \\
\hline happiness & 0.553 & 7.535 & 0.000 \\
\hline proactive coping & 0.224 & 3.024 & 0.003 \\
\hline presence of meaning & -0.225 & -3.020 & 0.003 \\
\hline adjusted R square & \multicolumn{3}{|c|}{0.709} \\
\hline $\mathrm{F}$ & \multicolumn{3}{|c|}{69.315} \\
\hline sig. & \multicolumn{3}{|c|}{0.000} \\
\hline
\end{tabular}

variables. It is preferred by people, assessing their incomes as low. Unemployed are less inclined to seek emotional support. Happiness is positively related to proactive coping, reflective coping, strategic planning, emotional support seeking, life satisfaction, resilience, autonomy, competence and relatedness. It is lower when the behaviour is avoiding and people report presence of meaning, which suggests that coping relates to the emotional well-being as well, except for the preventive behaviour and the daily instrumental support seeking, related to the cognitive component. Life satisfaction is higher when higher are the proactive and reflective behaviours, strategic planning, emotional and instrumental support seeking, resilience, when the basic psychological needs of autonomy, competence, and relatedness are supported and people are happy. It is lower when people prefer avoiding behaviour and have rigid presence of meaning.

Presence of meaning is supported by avoidance coping and correlates negatively with proactive coping, reflective coping, strategic planning, emotional support seeking, life satisfaction, resilience, autonomy, competence, relatedness. Moreover, it correlates negatively also with search for meaning. Predictors of happiness are life satisfaction and resilience. Life satisfaction is predicted by proactive behaviors, experienced happiness and less presence of meaning.

\section{Discussion}

Our expectations were partially confirmed. Happiness and life satisfaction are predicted by resilience and the basic psychological needs of being autonomous, feeing competent, and relatedness. Strong effect is accounted only for proactive coping.

All coping strategies correlate positively, which means that they support each 
other. Coping strategies have many main effects. The negative accounted effect is for avoidance behaviour. The higher is the avoidance, the worse are all other coping strategies. Avoidance leads to sharing beliefs in magic, suggesting that passive behaviours do not support well-being because of the lack of control. This means that avoidance is not healthy strategy, except for if for a very limited period. Furthermore, the better developed are the coping strategies, the higher is the effect on well-being in general. Proactive coping has effect on most of the psychological variables. It supports reflective, instrumental and emotional seeking, strategic planning and preventive coping. Proactive coping predicts life satisfaction and happiness, higher autonomy, competence and relatedness as basic needs. This supports the idea that proactive coping namely can be promoted in view to ensure better person-environment transactions and higher well-being.

The results support the position that life meaning and search of meaning are quire opposite (Steger et al., 2006). Presence of meaning deserves special attention. It has negative relations to coping strategies, not only to search of meaning. It seems that if person strongly maintains the commitments, she figuratively stops to develop. For this sample, exploration, adaptation, and search reveal the healthier path of development. Adaptive promoter of well-being seems to be the dynamic attitude, but reliance on fixed commitments, i.e. presence of meaning, reflects negatively on basic needs and life satisfaction.

Conspiracy beliefs do not correlate with psychological dimensions. This is important also because it supports the fact that sharing conspiracy theories depends on the social context and has nothing to do with personal search of meaning and psychological needs. Coping is important on personal level as it is designated to maintain good transactions with the environment. When it comes to issues out of personal control, this "meta" coping can be employed to reduce and maintain stress and lack of fulfilled psychological needs. This is supported by the relations between some of the coping strategies and belief in magic.

Predictors of happiness are life satisfaction and resilience. Happiness is higher when the perceived life satisfaction and resilience are higher. Predictors of life satisfaction are happiness, proactive coping and not fixed presence of meaning. Life satisfaction is promoted by proactive coping behavior and happiness and when there is less presence of meaning.

The strong role of proactive behaviour accounted reveals that this is the most adaptive behaviour. On its turn, it can be further promoted. The proactive coping is focused on long-future oriented behaviours that occur prior to the real stress episode. The proactive coping perceives the challenges as opportunity for development. It comprises strategies and vision for future and leads to accumulation of resources. The dynamics of exploration obviously promotes basic psychological needs and life satisfaction, contrary to presence of meaning. The results support that the context imposes flexible behaviours and life attitude. For the studied sample, it is evidenced that maintaining commitments is not "healthy". Furthermore, presence of meaning has the only positive correlation with avoidance coping. Both avoidance and presence of meaning result in less 


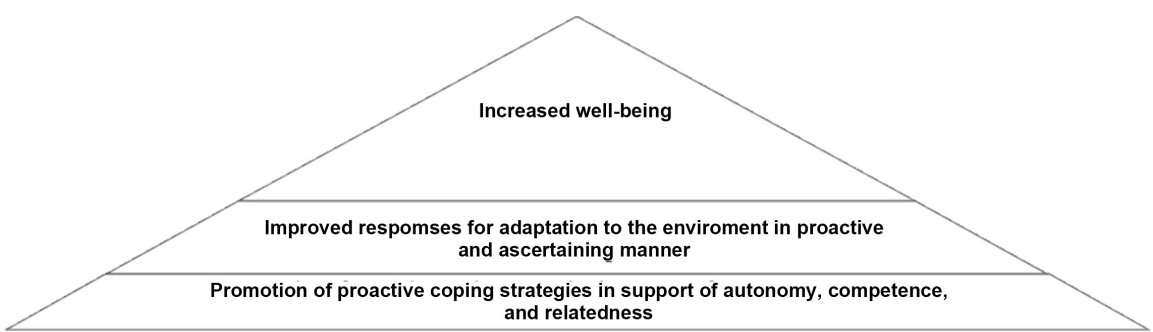

Figure 3. Theoretical framework of training objective.

experienced happiness and life satisfaction.

This gives unlimited opportunities for models and trainings focused on promotion of self-reflection skills and improvement of personal stress management skills (Figure 3). This can result in better ways for coping with stress and accumulation of resources, ensuring better adaptation to the environmental requirements and inner transformations. The main position we suggest is that promotion of self-reflection and successful proactive thinking and behaviour can become a component of the optimal functioning. This general framework can be applied to each life domain: profession, life philosophy, intimate relations, friendships, etc.

As an exemplary training programme, we propose the Three steps for promotion of proactive coping strategies. First of all, people have to confess what like and dislike. Afterwards to interpret and reinterpret this in a new light. Self-knowledge-the first step-means the person to become aware of her goals, motivation, and strives. The second step, self-acceptance, means unconditional acceptance of own advantages and disadvantages. The third step-self-expression is behaviour, consistent with personal goals and affiliations. These steps ensure balanced and integrated self. In respect to operationalization, this means awareness of the proactive subjectively preferred behaviours, experiencing their effect and consistency in their implementation and expansion in daily life. Nevertheless, the limitations due to the country-specific convenient sample, we consider data contribute to outlining a specific path of responses to intrinsic and extrinsic changes experienced. This gives raise to further study of proactive coping relations to flourishing in general.

\section{Conflicts of Interest}

The author declares no conflicts of interest regarding the publication of this paper.

\section{References}

Bakalova, B., Bakracheva, M., \& Mizova, B. (2015). Happiness and Life Satisfaction: In Search for Ourselves, Sofia, Colbis (in Bulgarian).

Bakracheva, M. (2017). Identity and Coping. Sofia, Colbis.

Bakracheva, M., \& Totseva, Y. (2018). Contextualand Individual Factors Determining the Belief in Conspiracy Theories in Bulgaria. In: M. Mulalić, N. Obralić, A. Mulalić, \& E. 
Jelešković (Eds.), The Future of Humanities, Education and Creative Industries (pp. 304-323). Sarajevo: International University of Sarajevo.

Baumeister, R. F. (1991). Meanings of Life. New York: Guilford.

Brotherton, R., \& French, C. C. (2014). Belief in Conspiracy Theories and Susceptibility to the Conjunction Fallacy. Applied Cognitive Psychology, 28, 238-248.

https://doi.org/10.1002/acp.2995

Chen, B., Vansteenkiste, M., Beyers, W., Boone, L., Deci, E., Van der Kaap-Deeder, J., Duriez, B., Lens, W., Matos, L., Mouratidis, A., Ryan, R., Sheldon, K., Soenens, B., Van Petegem, S., \& Verstuyf, J. (2015). Basic Psychological Need Satisfaction, Need Frustration, and Need Strength across Four Cultures. Motivation and Emotion, 39, 216-236. https://doi.org/10.1007/s11031-014-9450-1

Compas, B. E., Connor-Smith, J. K., Saltzman, H., Thomsen, A. H., \& Wadsworth, M. E. (2001). Coping with Stress during Childhood and Adolescence: Problems, Progress, and Potential in Theory and Research. Psychological Bulletin, 127, 87-127. https://doi.org/10.1037//0033-2909.127.1.87

Connor-Smith, J. K., \& Flachsbart, C. (2007). Relations between Personality and Coping: A Meta-Analysis. Journal of Personality and Social Psychology, 93, 1080-1107. https://doi.org/10.1037/0022-3514.93.6.1080

Dagnall, N., Drinkwater, K., Parker, A., Denovan, A., \& Parton, M. (2015). Conspiracy Theory and Cognitive Style: A worldview. Frontiers in Psychology, 6, 206. https://doi.org/10.3389/fpsyg.2015.00206

Deci, E. L., \& Ryan, R. M. (1985). The General Causality Orientations Scale: Self Determination in Personality. Journal of Research in Personality, 19, 109-134. https://doi.org/10.1016/0092-6566(85)90023-6

Diener, E. (1984). Subjective Well-Being. Psychological Bulletin, 95, 542-575. https://doi.org/10.1037/0033-2909.95.3.542

Diener, E., Emmons, R. A., Larson, R. J., \& Griffin, S. (1985). The Satisfaction with Life Scale. Journal of Personality Assessment, 49, 71-75. https://doi.org/10.1207/s15327752jpa4901 13

Folkman, S., \& Lazarus, R. S. (1980). An Analysis of Coping in a Middle-Aged Community Sample. Health and Social Behavior, 21, 219-239. https://doi.org/10.2307/2136617

Frankl, V. E. (1969). The Will to Meaning: Foundations and Applications of Logotherapy. New York: New American Library.

Frankl, V. E. (2006). Man’s Search for Meaning. Boston, MA: Beacon Press.

Greenglass, E., Schwarzer, R., \& Taubert, S. (1999). The Proactive Coping Inventory (PCI): A Multidimensional Research Instrument. 20th International Conference of the Stress and Anxiety Research Society (STAR), Cracow, Poland, July 12-14 1999. https://doi.org/10.1037/t07292-000

Haan, N. (1977). A Tripartite Model of Ego Functioning: Values and Clinical Research Applications. The Journal of Nervous Mental Disorders, 148, 14-30. https://doi.org/10.1097/00005053-196901000-00003

Hobfoll, S. E., \& Leiberman, J. R. (1987). Personality and Social Resources in Immediate and Continued Stress-Resistance among Women. Journal of Personality and Social Psychology, 52, 18-26. https://doi.org/10.1037/0022-3514.52.1.18

Hobfoll, S. E., \& Lilly, R. S. (1993). Resource Conservation as a Strategy for Community Psychology. Journal of Community Psychology, 21, 128-148. 
https://doi.org/10.1002/1520-6629(199304)21:2<128::AID-JCOP2290210206>3.0.CO;2$\underline{5}$

Huta, V., \& Ryan, R. M. (2010). Pursuing Pleasure or Virtue: The Differential and Overlapping Well-Being Benefits of Hedonic and Eudaimonic Motives. Journal of Happiness Studies: An Interdisciplinary Forum on Subjective Well-Being, 11, 735-762. https://doi.org/10.1007/s10902-009-9171-4

Huyck, M. H. (1993). Middle Age. Academic American Encyclopaedia, 13, 390-391.

Kim-Cohen, J., \& Turkewitz, R. (2012). Resilience and Measured Gene-Environment Interactions. Development and Psychopathology, 24, 1297-1306. https://doi.org/10.1017/S0954579412000715

King, L. A., Hicks, J. A., Krull, J. L., \& Del Gaiso, A. K. (2006). Positive Affect and the Experience of Meaning in Life. Journal of Personality and Social Psychology, 90, 179-196. https://doi.org/10.1037/0022-3514.90.1.179

Klinger, E. (1998). The Search for Meaning in Evolutionary Perspective and Its Clinical Implications. In P. T. P. Wong, \& P. S. Fry (Eds.), The Human Quest for Meaning: A Handbook of Psychological Research and Clinical Application (pp. 27-50). Mahwah, NJ: Lawrence Erlbaum Associates.

Lachman, M. E. (2004). Development in Midlife. Annual Review of Psychology, 55, 305-331. https://doi.org/10.1146/annurev.psych.55.090902.141521

Lazarus R. S., \& Folkman, S. (1984). Stress, Appraisal and Coping. New York: Springer.

Lazarus, R. S. (1966). Psychological Stress and the Coping Process. New York: McGraw-Hill.

Lee, T. S., Tzeng, W. C., \& Chiang, H. H. (2019). Impact of Coping Strategies on Nurses' Well-Being and Practice. Journal of Nursing Scholarship, 51, 195-204. https://doi.org/10.1111/jnu.12467

Maddi, S. R. (1970). The Search for Meaning. In M. Page (Ed.), Nebraska Symposium on Motivation (pp. 137-186). Lincoln, NE: University of Nebraska Press.

Mascaro, N., \& Rosen, D. H. (2005). Existential Meaning's Role in the Enhancement of Hope and Prevention of Depressive Symptoms. Journal of Personality, 73, 985-1013. https://doi.org/10.1111/j.1467-6494.2005.00336.x

Mascaro, N., \& Rosen, D. H. (2006). The Role of Existential Meaning as a Buffer against Stress. Journal of Humanistic Psychology, 46, 168-190. https://doi.org/10.1177/0022167805283779

Maslow, A. H. (1954). Motivation and Personality. New York: Harper \& Row.

Menninger, K. (1954). Regulatory Devices of the Ego under Major Stress. International Journal of Psychoanalysis, 35, 412-420.

Pietrzak, R. H., \& Southwick, S. M. (2011). Psychological Resilience in OEF-OIF Veterans: Application of a Novel Classification Approach and Examination of Demographic and Psychosocial Correlates. Journal of Affect Disorders, 133, 560-568. https://doi.org/10.1016/j.jad.2011.04.028

Reiss, S., \& Havercamp, S. M. (2005). Motivation in a Developmental Context: A New Method for Studying Self-Actualization. Journal of Humanistic Psychology, 45, 41-53. https://doi.org/10.1177/0022167804269133

Reker, G. T. (2000). Theoretical Perspective, Dimensions, and Measurement of Existential Meaning. In G. T. Reker, \& K. Chamberlain (Eds.), Exploring Existential Meaning: Optimizing Human Development across the Life Span (pp. 39-58). Thousand Oaks, CA: Sage Publications. https://doi.org/10.4135/9781452233703.n4 
Reker, G. T. (2005). Meaning in Life of Young, Middle-Aged, and Older Adults: Factorial Validity, Age, and Gender Invariance of the Personal Meaning Index (PMI). Personality and Individual Differences, 38, 71-85. https://doi.org/10.1016/j.paid.2004.03.010

Ryan, R. M. (1995). Psychological Needs and the Facilitation of Integrative Processes. Journal of Personality, 63, 397-427. https://doi.org/10.1111/j.1467-6494.1995.tb00501.x

Ryan, R. M., \& Deci, E. L. (2000). The Darker and Brighter Sides of Human Existence: Basic Psychological Needs as a Unifying Concept. Psychological Inquiry, 11, 319-338. https://doi.org/10.1207/S15327965PLI1104 03

Ryff, C. D. (1989). Happiness Is Everything, or Is It? Explorations on the Meaning of Psychological Well-Being. Journal of Personality and Social Psychology, 57, 1069-1081. https://doi.org/10.1037/0022-3514.57.6.1069

Ryff, C. D., \& Singer, B. H. (1998). The Contours of Positive Human Health. Psychological Inquiry, 9, 1-28. https://doi.org/10.1207/s15327965pli0901 1

Selye, H, (1976). The Stress of Life. New York: McGraw-Hill.

Shek, D. T. L. (1996). Mid-Life Crisis in Chinese Men and Women. Journal of Psychology, 130, 109-119.

Sherrieb, K., Norris, F. H., \& Galea, S. (2010). Measuring Capacities for Community Resilience. Social Indicators Research, 99, 227-247.

https://doi.org/10.1007/s11205-010-9576-9

Smith, B. W., Dalen, J., Wiggins, K., Tooley, E., Christopher, P., \& Bernard, J. (2008). The Brief Resilience Scale: Assessing the Ability to Bounce Back. International Journal of Behavioral Medicine, 15, 194-200. https://doi.org/10.1080/10705500802222972

Southwick, M., Bonanno, G., Masten, S., Panter-Brick, C., \& Yehuda, R. (2014). Resilience Definitions, Theory, and Challenges: Interdisciplinary Perspectives. European Journal of Psychotraumatology, 5, Article No. 25338. https://doi.org/10.3402/ejpt.v5.25338

Steger, M. F., \& Frazier, P. (2005). Meaning in life: One link in the Chain from Religion to Well-Being. Journal of Counseling Psychology, 52, 574-582.

https://doi.org/10.1037/0022-0167.52.4.574

Steger, M. F., Frazier, P., Oishi, S., \& Kaler, M. (2006). The Meaning in Life Questionnaire: Assessing the Presence of and Search for Meaning in Life. Journal of Counseling Psychology, 53, 80-93. https://doi.org/10.1037/0022-0167.53.1.80

Steger, M. F., Kashdan, T. B., Sullivan, B. A., \& Lorentz, D. (2008). Understanding the Search for Meaning in Life: Personality, Cognitive Style, and the Dynamic between Seeking and Experiencing Meaning. Journal of Personality, 76, 199-228.

Swami, V., Coles, R., Stieger, S., Pietschnig, J., Furnham, A., Rehim, S., \& Voracek, M. (2011). Conspiracist Ideation in Britain and Austria: Evidence of a Monological Belief System and Associations between Individual Psychological Differences and Real-World and Fictitious Conspiracy Theories. British Journal of Psychology, 102, 443-463. https://doi.org/10.1111/j.2044-8295.2010.02004.x

Urry, H. L., Nitschke, J. B., Dolski, I., Jackson, D. C., Dalton, K. M., Mueller, C. J. et al. (2004). Making a Life Worth Living: Neural Correlates of Well-Being. Psychological Science, 15, 367-372. https://doi.org/10.1111/j.0956-7976.2004.00686.x

Vaillant, G. E. (1977). Adaptation to Life. Boston, MA: Little Brown and Co.

Walsh, F. (2006). Strengthening Family Resilience (2nd ed., 384 p.). New York: Guilford Press.

Wrosch, C., Scheier, M. F., Carver, C. S., \& Schulz, R. (2003). The Importance of Goal Disengagement in Adaptive Self-Regulation: When Giving Up Us Beneficial. Self and 
Identity, 2, 1-20. https://doi.org/10.1080/15298860309021

Yang, Y. T. (2010). Stress, Coping, and Psychological Well-Being: Comparison among American and Asian International Graduate Students from Taiwan, China, and South Korea. PhD Thesis, Lawrence, KS: University of Kansas. http://hdl.handle.net/1808/6747 